\title{
OLIGARQUÍA Y FISCALIDAD: \\ LOS PRIMEROS PASOS \\ DE LA CONTRIBUCIÓN DE INMUEBLES, \\ CULTIVO Y GANADERÍA \\ EN LA PROVINCIA DE ALICANTE
}

PEDRO DÍAZ MARÍN

Universidad de Alicante

\section{RESUMEN}

El objetivo del artículo es analizar la andadura de la contribución territorial en la provincia de Alicante durante la Década Moderada (1844-1854). Además del análisis de la estructura de la contribución territorial $\longrightarrow$ el cupo y sus recargos-, se estudia también el reparto del impuesto entre los pueblos de la provincia, así como el reparto individual entre los contribuyentes de la ciudad de Alicante y su comarca. Una mejor comprensión de las implicaciones sociales y políticas de la nueva figura tributaria hace también necesaria la referencia a las protestas de pueblos y particulares ante los repartos efectuados por las oligarquías provinciales y locales, protestas que evidencian tanto la injusticia que presidió esos repartos, como las resistencias que provocó el impuesto, y que se tradujeron en un alto nivel de fraude.

\section{ABSTRACT}

This article aims to analyze the territorial taxes in the province of Alicante during the Década Moderada (1844-1854). Besides a structural analysis of the territorial taxes -quota and its charges-, the sharing out of taxes among the villages of the province, as well as the individual share of taxpayers in the town of Alicante and its province will be studied. Reference to the objections from villages and individuals to the sharing out effected by the provincial and local oligarchy is therefore necessary in order to understand the political and social implications of the new tax. Such objections show the extent to which the sharing out was unfair and the resistance offered towards the taxes, which resulted in high levels of tax evasion. 
Es conocida la importancia económica, social y política de la contribución de inmuebles, cultivo y ganadería que la reforma tributaria de Mon y Santillán puso en marcha a partir de 1845. Dicha reforma formaba parte de un proyecto político más ambicioso que buscaba remodelar el Estado de acuerdo a criterios de mayor eficacia, al tiempo que ampliaba sus competencias. El artículo pretende contribuir a un mejor conocimiento de la aplicación del impuesto en el doble ámbito provincial —mediante el análisis de los repartos efectuados por la Diputación o por los funcionarios de Hacienda - y local -a través del estudio del reparto realizado en 1852 por la comisión de evaluación y repartimiento en la ciudad de Alicante y su comarca- ${ }^{1}$. Se adopta una perspectiva de naturaleza básicamente política que busca contextualizar la aplicación de la contribución territorial en el ámbito de la política provincial y de la red de intereses de las oligarquías que mediatizaron su gestión.

\section{LA CONTRIBUCIÓN TERRITORIAL: EL CUPO Y SUS RECARGOS}

En el nuevo modelo de Estado que los moderados diseñaron a partir de 1844 ocupó un papel central la reforma tributaria de Mon y Santillán ${ }^{2}$, una de cuyas piezas clave fue la contribución territorial. Este impuesto pronto se convirtió en un elemento importante de la revolución liberal al propiciar la disolución de las viejas formas de producción en la medida en que hizo «inviables las explotaciones campesinas que no fuesen capaces de unos niveles mínimos de comercialización, de integración en el mercado» ${ }^{3}$. Pero, al mismo tiempo, el sistema de reparto y recaudación de la contribución territorial puso de manifiesto la injusticia -una injusticia heredada, por otra parte- del sistema fiscal montado por Mon. El gobierno asignaba el cupo a cada provincia y las diputaciones efectuaban el reparto entre los municipios, que a su vez fijaban la cuota a cada contribuyente. Ahora bien, como veremos, los cupos se asignaron sin que existiera una estadística fiable de la riqueza territorial, ya que ésta se realizaba a partir de las declaraciones de los propietarios a las comisiones de evaluación

' Son escasos los estudios sobre la hacienda de la provincia de Alicante en esta época, Vidal (1994). Salvador Salort (1998) ha estudiado la hacienda local de Alicante. Jesús Millán (1999) extrae interesantes conclusiones de las fuentes fiscales para la Vega Baja.

2 Comín (1988 y 1996), Estapé (1971), Fontana (1977) y Artola (1986).

${ }^{3}$ Fontana (1977), p. 338. 


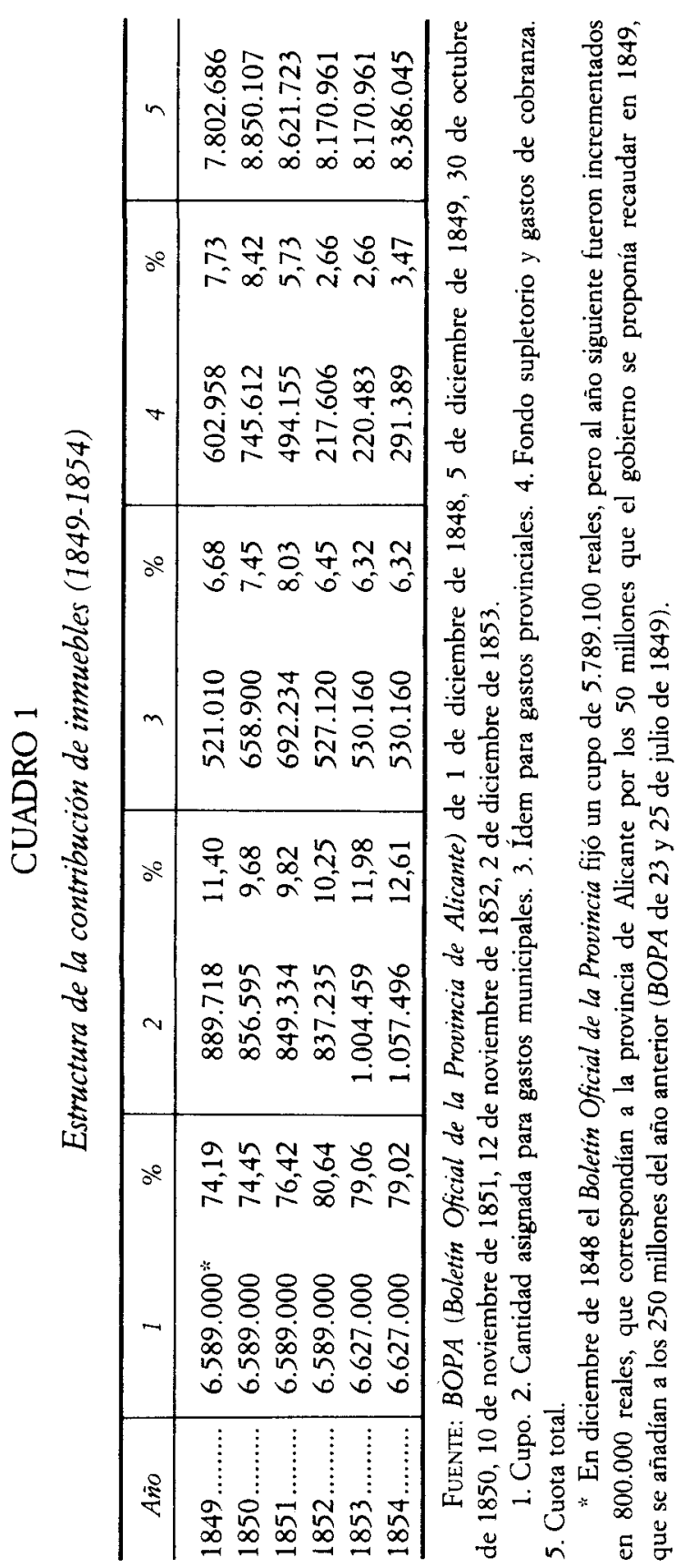


y repartimiento, formadas por los primeros contribuyentes, que acababan aceptando las ocultaciones de aquéllos. Además, hay que tener en cuenta que también los ayuntamientos estaban formados por los grandes contribuyentes, que actuaron como defensores de los intereses de la oligarquía, dado que el moderantismo favoreció la ocupación de los centros de poder por un exiguo grupo de ciudadanos mediante la concesión de los derechos políticos a una reducida élite de comerciantes, propietarios y unos pocos profesionales liberales ${ }^{4}$. Por otro lado, no hay que olvidar que el sistema de cupo impedía que las ocultaciones redujeran los ingresos del Tesoro, ya que el fraude de unos contribuyentes lo pagaban otros, de ahí las continuas reclamaciones de agravio y las protestas contra el cupo tanto de los particulares como de los pueblos. Con todo, no se debe perder de vista, como ha señalado recientemente Francisco Comín, que «el nuevo régimen fiscal era formalmente menos injusto que el absolutista» 5 .

El cupo asignado por contribución territorial a la provincia de Alicante varió desde los 6.100 .000 reales en $1846^{\circ}$ a más de 6,6 millones en 1854 , un 8,63 por 100 . Al cupo asignado por el Tesoro se añadían otras cantidades en concepto de gastos municipales y provinciales, fondo supletorio y gastos de cobranza, que supusieron un incremento sobre el cupo de más del 30 por 100 durante el bienio 1849-1851, bajando a algo más del 24 por 100 en 1853-1854. El mayor incremento sobre el cupo correspondía a gastos municipales y provinciales que, en conjunto, representaron un aumento superior al 20 por 100 , presionando los gastos municipales entre el 13 y el 16 por 100 , mientras que los provinciales oscilaron entre el 8 y el 10,5 por 100 del cupo. El fondo supletorio suponía el 5 por 100 de la suma del cupo más los gastos municipales y provinciales, y el 4 por 100 de gastos de cobranza se calculaba sobre el cupo, los gastos municipales y provinciales y el fondo supletorio. Estas últimas partidas gravaron el cupo entre el 3,3 y el 11,3 por 100 (cuadro 2). Por Real Decreto de 16 de abril de 1851 Bravo Murillo rebajó el recargo máximo de los gastos de cobranza al 3 por 100 y suprimió el fondo supletorio, fijando, en caso

+ En la ciudad de Alicante el número de electores en las elecciones locales durante la Década Moderada rondó los 500, mientras que el de elegibles se situó en torno a los 200, lo que suponía el 12 y el 5 por 100 aproximadamente del vecindario, Díaz (1998), p. 149.

${ }^{5}$ Comin (1998), p. 233.

- En el reparto aprobado por Real Decreto de 26 de julio de 1845 el gobierno fijó para Alicante un cupo de 7.314 .000 reales, unos 500.000 reales menos que el establecido inicialmente por Santillán, que fue de 7.813 .915 reales, Estapé (1971), p. 135. 


\section{CUADRO 2}

Incremento de los gastos municipales, provinciales, fondo supletorio y cobranza sobre el cupo (en porcentaje)

\begin{tabular}{cccc}
\hline Año & Gastos municipales & Gastos provinciales & $\begin{array}{c}\text { Fondo suplotorio y gastos } \\
\text { de cobranza }\end{array}$ \\
\hline $1849 \ldots \ldots \ldots \ldots$. & 15,37 & 9,00 & 10,42 \\
$1850 \ldots \ldots \ldots \ldots$. & 13,00 & 10,00 & 11,32 \\
$1851 \ldots \ldots \ldots \ldots$. & 12,84 & 10,51 & 7,50 \\
$1852 \ldots \ldots \ldots \ldots$. & 12,71 & 8,00 & 3,30 \\
$1853 \ldots \ldots \ldots \ldots$. & 15,16 & 8,00 & 3,33 \\
$1854 \ldots \ldots \ldots \ldots$ & 15,96 & 8,00 & 4,40 \\
\hline
\end{tabular}

FUENTE: BOPA de 1 de diciembre de 1849, 30 de octubre de 1850, 10 de noviembre de 1851, 12 de noviembre de 1852, 2 de diciembre de 1853 .

necesario, un reparto que se haría efectivo en el último mes del año, limitado al importe de las partidas fallidas ${ }^{7}$.

Esta presión sobre el cupo no alcanzó los mismos niveles en todos los pueblos. Mientras que los gastos provinciales presionaron de forma homogénea en toda la provincia, el recargo sobre los gastos municipales osciló mucho, desde el 20 por 100 aproximadamente en Alcoy, Villajoyosa, Callosa d'En Sarrià o Novelda hasta menos del 2 por 100 en Orihuela, o cerca del 3 por 100 (1851) o 9 por 100 (1853) en Elche. El resto de los partidos recargaron el cupo entre el 11 y el 17 por 100 (cuadro 3).

Estas grandes variaciones se explican en algunos casos por lo reducido de los déficits municipales, que no hacía necesario establecer un recargo excesivo sobre el cupo de inmuebles, caso de ciudades como Orihuela o Elche, cuyos presupuestos contemplaban un déficit en 1848 de tan sólo 34.855 reales o de 26.889 reales, respectivamente, pero lo más frecuente era que los ayuntamientos cargaran la presión sobre el consumo ${ }^{8}$. El Ayun-

'BOPA de 23 de abril de 1851.

${ }^{8}$ Guerra (1848). En 1848 los ayuntamientos de la provincia de Alicante presupuestaron un déficit de más de dos millones de reales, que fue cubierto mediante el recargo a las contribuciones estatales, aportando los impuestos sobre consumos el 38 por 100 de los ingresos totales y el 62,3 por 100 de los medios propuestos para cubrir el déficit.

Por lo que respecta a la ciudad de Alicante, entre 1849 y 1854 los impuestos directos contribuyeron entre un 5,4 y un 12,8 por 100 -n el caso de la contribución de inmuebles-, 


\section{CUADRO 3}

Incremento de los gastos municipales y de los gastos provinciales sobre el cupo (en porcentaje)

\begin{tabular}{|c|c|c|c|c|}
\hline \multirow{2}{*}{ Partido } & \multicolumn{2}{|c|}{ Gastos municipales } & \multicolumn{2}{|c|}{ Gastos provinciales } \\
\hline & 1851 & 1853 & 1851 & 1853 \\
\hline 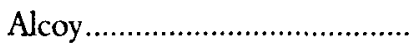 & 20,00 & 21,95 & 10,07 & 8,00 \\
\hline 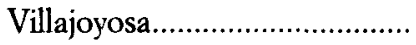 & 19,90 & 19,19 & 10,07 & 8,00 \\
\hline C. d'En Sarrià & 19,31 & 19,23 & 10,07 & 8,00 \\
\hline 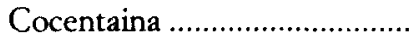 & 17,36 & 15,59 & 10,07 & 8,00 \\
\hline 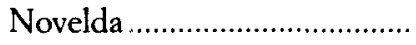 & 17,11 & 20,33 & 11,42 & 8,00 \\
\hline 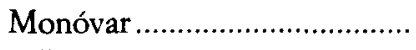 & 17,00 & 15,69 & 10,07 & 8,00 \\
\hline 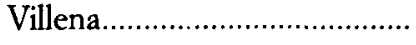 & 16,98 & 17,67 & 10,08 & 8,00 \\
\hline 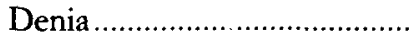 & 14,98 & 14,88 & 10,08 & 7,95 \\
\hline 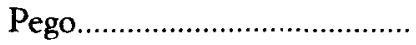 & 14,28 & 15,76 & 9,20 & 8,00 \\
\hline 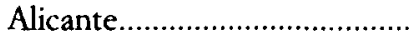 & 11,54 & 12,77 & 10,09 & 8,47 \\
\hline 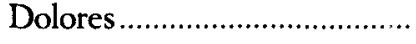 & 9,96 & 17,60 & 10,63 & 8,00 \\
\hline Jijona & 8,12 & 18,54 & 10,08 & 8,00 \\
\hline Elche. & 2,73 & 9,10 & 10,08 & 8,00 \\
\hline 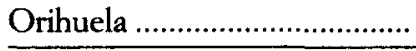 & 1,24 & 1,71 & 13,51 & 8,00 \\
\hline Media provincial ................... & 12,89 & 15,72 & 10,53 & 8,00 \\
\hline
\end{tabular}

FUENTE: BOPA de 30 de octubre de 1850 y 12 de noviembre de 1852 .

tamiento alicantino justificaba semejante discriminación con el argumento de que el gravamen sobre la riqueza territorial o comercial iba en detrimento de los intereses de los propietarios, que hacía extensivos al conjunto de la sociedad. Consideraba el cabildo que tanto la riqueza territorial como la comercial estaban sobrecargadas, en cambio, el impuesto indirecto «ya por el modo de exigirse, ya por estar de antiguo sancionado por la costumbre es el más suave y que más posibilidades puede ofrecer para dar los productos que se desean» 9 .

y un 2,17 y un 10,5 por 100 -en el caso del subsidio industrial y de comercio-, mientras que los impuestos indirectos, los consumos, aportaron más de la mitad de los ingresos a las arcas municipales, llegando algunos años a superar el 75 por 100. Díaz (1998), p. 373. Según cálculos de Salvador Salort (1998), los impuestos indirectos supusieron para la hacienda local más del 66 por 100 de todos los ingresos recaudados entre 1846 y 1874, pp. 252-253.

${ }^{9}$ Díaz (1998), p. 370. 
La Diputación repartía el cupo y los recargos entre los municipios agrupados en partidos judiciales. Los partidos de Denia, Elche y Orihuela aportaban en torno al 30 por 100 del cupo. Otros cuatro partidos: Cocentaina, Dolores, Alcoy y Alicante contribuían con algo más del 30 por 100 , mientras que menos del 40 por 100 del cupo se lo repartían los otros siete partidos: Jijona, Villena, Novelda, Callosa d'En Sarrià, Pego, Monóvar y Villajoyosa, a los que se añadió Almoradí en 1853 (cuadro 4).

\section{CUADRO 4}

Distribución de la contribución de inmuebles de 1851 y 1853

(en porcentaje)

\begin{tabular}{|c|c|c|c|c|c|c|c|c|}
\hline \multirow[t]{2}{*}{ Partido } & \multicolumn{2}{|c|}{ Cupo } & \multicolumn{2}{|c|}{$\begin{array}{c}\text { Gastos } \\
\text { municipales }\end{array}$} & \multicolumn{2}{|c|}{$\begin{array}{c}\text { Gastos } \\
\text { provinciales }\end{array}$} & \multicolumn{2}{|c|}{ Cuota } \\
\hline & 1851 & 1853 & 1851 & 1853 & 1851 & 1853 & 1851 & 1853 \\
\hline Alicante. & 6,74 & 6,38 & 6,04 & 5,38 & 6,46 & 6,34 & 6,66 & 6,26 \\
\hline Alcoy... & 8,29 & 8,1 & 12,85 & 11,72 & 7,92 & 8,07 & 8,75 & 8,56 \\
\hline C. d'En Sarrià & 6,36 & 6,51 & 9,52 & 8,26 & 6,22 & 6,49 & 6,70 & 6,73 \\
\hline Cocentaina. & 8,78 & 8,78 & 11,83 & 9,02 & 8,39 & 8,74 & 9,11 & 8,80 \\
\hline Denia. & 10,61 & 10,61 & 12,33 & 10,41 & 10,16 & 10,50 & 10,77 & 10,57 \\
\hline Elche. & 8,48 & 8,44 & 1,80 & 5,07 & 8,12 & 8,42 & 7,77 & 8,03 \\
\hline Dolores. & 8,40 & 9,70 & 6,49 & 11,29 & 8,47 & 9,66 & 8,59 & 9,90 \\
\hline Jijona . & 6,64 & 6,60 & 4,19 & 8,06 & 6,36 & 6,57 & 6,38 & 6,90 \\
\hline Monóvar. & 4,49 & 3,96 & 5,93 & 4,10 & 4,30 & 3,95 & 4,64 & 3,86 \\
\hline Novelda..... & 6,05 & 5,90 & 8,03 & 7,92 & 6,56 & 5,88 & 6,31 & 6,15 \\
\hline Orihuela . & 9,55 & 9,61 & 0,92 & 1,08 & 12,25 & 9,57 & 8,88 & 8,50 \\
\hline Pego... & 5,96 & 5,34 & 6,61 & 5,56 & 5,20 & 5,32 & 5,43 & 5,37 \\
\hline Villajoyosa... & 3,36 & 3,48 & 5,18 & 4,40 & 3,21 & 3,47 & 3,53 & 3,60 \\
\hline Villena............ & 6,29 & 6,61 & 8,28 & 7,69 & 6,02 & 6,57 & 6,49 & 6,73 \\
\hline
\end{tabular}

FUENTE: BOPA de 30 de octubre de 1850 y 12 de noviembre de 1852 .

En cuanto al reparto por pueblos, según se desprende del cuadro 5, más de la mitad del cupo lo cubrían aproximadamente entre 12 y 16 municipios, aportando cada uno cantidades por encima de los 100.000 reales. Entre 16 y 20 municipios contribuían con cuotas comprendidas entre los 50.000 y los 100.000 reales y aportaban en torno a la quinta 


\section{CUADRO 5}

Estructura de la contribución territorial por municipios

\begin{tabular}{|c|c|c|c|c|c|c|}
\hline \multirow{2}{*}{$A \tilde{n} O$} & \multicolumn{2}{|c|}{ Más de 100.000 reales } & \multicolumn{2}{|c|}{$50.000-100.000$ reales } & \multicolumn{2}{|c|}{ Menos de 50.000 reales } \\
\hline & Número & Cupo (\%) & Número & Cupo (\%) & Número & Cupo (\%) \\
\hline 1848. & 12 & 50,47 & 20 & 23,04 & 115 & 26,47 \\
\hline 1849. & 13 & 49,38 & 18 & 21,80 & 111 & 28,82 \\
\hline $1850 \ldots \ldots$ & 16 & 54,19 & 16 & 17,73 & 110 & 28,08 \\
\hline
\end{tabular}

FUENTE: Diaz (1998), p. 391.

parte del cupo; mientras que más del centenar de municipios pagaban alrededor del 28 por $100^{10}$. Veamos ahora cómo se repartía el impuesto a nivel individual, para lo cual disponemos del reparto efectuado en 1852 .

\section{LOS REPARTIMIENTOS INDIVIDUALES: LA CONTRIBUCIÓN TERRITORIAL DE 1852 EN LA CIUDAD DE ALICANTE Y SU TÉRMINO}

El cupo asignado en 1852 por contribución territorial a la ciudad de Alicante y su comarca fue de 303.000 reales, a los que se añadieron 53.789 reales en concepto de gastos municipales, provinciales y de cobranza -lo que supuso un incremento de más del 17 por $100-$, que elevó a 356.789 reales el líquido a repartir por la comisión de evaluación y repartimiento de la ciudad (cuadro 6). Como muestra el cuadro 7, existían 3.857 contribuyentes, de los que el 64,4 por 100 eran vecinos y el 35,6 por 100 forasteros. Un importante número de contribuyentes vecinos - algo más del 45 por 100 - habitaba fuera del casco urbano, en 22 partidas rurales, entre las que sobresalía Campello, que albergaba el mayor número de contribuyentes ( 371 ) y la mayor riqueza imponible ( 53.725 reales), seguido ya de lejos por Cañada y Moralet, con 132 y 117 contribuyentes res-

${ }^{10}$ Los municipios que contribuían con más de 100.000 reales eran los siguientes: Orihuela, Alcoy, Elche, Alicante, Villena, Cocentaina, Pego, Denia, Aspe, Jávea, Novelda, Crevillente, Villajoyosa y Callosa de Segura (BOPA de 16 de noviembre de 1849 y 12 de noviembre de 1852). 


\section{CUADRO 6}

Contribución territorial de 1852

de la ciudad de Alicante y su término

\begin{tabular}{|c|c|}
\hline Cupo. & 303.000 \\
\hline Gastos municipales $(6,6 \%)$. & 20.000 \\
\hline Gastos provinciales $(8 \%)$ & 24.240 \\
\hline 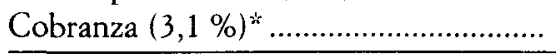 & 9.549 \\
\hline Total & 356.789 \\
\hline
\end{tabular}

* Los gastos de cobranza suponen el 2,7 por 100

del cupo más los gastos municipales y provinciales.

FUENTE: BOPA, 1852.

\section{CUADRO 7}

Estructura de la contribución territorial de 1852 de la ciudad de Alicante

\begin{tabular}{llllll}
\hline & \multicolumn{2}{c}{ Contribuyentes } & Riqueza imponible & Cuota & Gravamen \\
\hline Vecinos & Alicante & 1.355 & 1.832 .438 & 244.752 & 13,4 \\
& Partidas & 1.130 & 184.335 & 25.184 & 13,7 \\
\cline { 3 - 6 } & Total & 2.485 & $2.016 .773(75 \%)$ & $269.936(75,7 \%)$ & 13,5 \\
\cline { 3 - 6 } Forasteros & No residentes & 168 & 465.980 & 58.537 & 12,6 \\
& Residentes & 1.204 & 204.027 & 28.316 & 13,9 \\
\cline { 3 - 6 } & Total & 1.372 & $670.007(25 \%)$ & $86.853(24,3 \%)$ & 13,2 \\
\hline \multirow{2}{*}{ Total } & & 3.857 & 2.686 .780 & 356.789 & $13,3 \%$ \\
\hline
\end{tabular}

FUENTE: BOPA, 1852.

pectivamente ${ }^{11}$. Los contribuyentes catalogados como forasteros, o que al menos no aparecían incluidos en la relación de vecinos, suponían el 35,6 por 100 del total, aunque solamente el 12,3 por 100 residía fuera de la provincia, mientras que la gran mayoría, más del 87 por 100 , tenía

"Las partidas eran las siguientes: Aguas Bajas (23 contribuyentes), Albufera (7), Ángeles (7), Alcoraya (79), Barañes (14), Bacarot (27), Bavel (7), Condomina (28), Cañada (132), Campello (371), Fabraquer (34), Font-Calent (32), Monnegre (8), Moralet (117), Orgegia (19), Rebolledo (38), San Blas (3), Santa Faz (47), Tángel (35), Vallonga (14) y Verdegás (89), BOPA de 1852. Agradezco al profesor Jesús Millán haberme facilitado la consulta de esta fuente. 
su domicilio en lugares o pueblos cercanos a la ciudad de Alicante ${ }^{12}$, lo que implicaba que solamente el 4,3 por 100 del total de contribuyentes - vecinos y forasteros - residiera fuera de la provincia. Los vecinos acumulaban las tres cuartas partes de la riqueza, pagaban algo más del 75 por 100 de la cuota, y soportaban un gravamen del 13,5 por 100 , siendo ligeramente superior el de las partidas rurales al del casco urbano. El mismo fenómeno se observa entre los contribuyentes forasteros. De éstos, los residentes en la provincia acumulaban el 7,6 por 100 de la riqueza y aportaban el 8 por 100 de la cuota, siendo el tipo de gravamen del 13,9 por 100 ; mientras que los forasteros no residentes en la provincia veían gravada su riqueza en un 12,6 por 100 . En conjunto, los contribuyentes residentes en la provincia reunían el 82,7 por 100 de la riqueza y aportaban el 83,6 por 100 de la cuota, resultando un tipo de gravamen del 13,4 por 100 .

Como muestra el cuadro 8 , más de la mitad de la riqueza correspondía a inmuebles urbanos y edificios rústicos, en manos mayoritariamente de los vecinos. La mayor parte del ganado pertenecía a los habitantes de las partidas. Es importante subrayar el peso de la propiedad de los forasteros residentes fuera de la provincia, con el 17,3 por 100 de la riqueza, destacando el control de cerca del 40 por 100 del agua, algo fundamental en una zona de déficit hídrico como Alicante. Los vecinos disponían también de la mayor parte de las tierras, aunque la presencia de los forasteros no residentes no es desdeñable, con más de un 17 por 100 bajo su control.

Si hacemos un corte vertical (cuadro 9), observamos que 53 contribuyentes -el 1,4 por 100 -, con más de 1.000 reales de contribución, aportaban casi el 30 por 100 de la cuota total. Este grupo disponía de más de la cuarta parte de la riqueza agraria, más de la mitad del agua, cerca de la tercera parte de la riqueza urbana y sólo del 4,2 por $100 \mathrm{del}$ ganado. Algo más de 600 contribuyentes -el 15,7 por 100- pagaban entre 100 y 1.000 reales, disponían de poco más de la mitad de la riqueza y aportaban en torno al 49 por 100 de la cuota. En el extremo inferior de la escala se encontraba el 83 por 100 de los contribuyentes que pagaba menos de 100 reales, la mayoría -el 74,3 por 100 - menos de 50 . Estos últimos disponían tan sólo del 11,2 por 100 de la riqueza, pero pagaban el 14 por 100 de la cuota. Naturalmente estas enormes diferencias no eran exclusivas de Alicante. Jesús Millán ha señalado que en Orihuela los

${ }^{12}$ Los forasteros residentes en la provincia vivían en Aguas Altas, Aspe, Agost, Busot, Elche, Ibi, Jijona, Muchamiel, Monforte, Novelda, Orcheta, Relleu, San Juan y Benimagiell, San Vicente, Tibi, Villafranqueza y Villajoyosa. 


\section{CUADRO 8}

Estructura de la riqueza según la contribución de 1852

\begin{tabular}{|c|c|c|c|c|c|c|}
\hline & & Tierras & Agua & Casa & Ganaderia & Total \\
\hline \multirow[t]{3}{*}{ Vecinos } & Alicante & 302.311 & 12.066 & 1.509 .886 & 8.175 & 1.832 .438 \\
\hline & Partidas & 121.749 & 258 & 28.221 & 34.107 & 184.335 \\
\hline & Total & 424.060 & 12.324 & 1.538 .107 & 42.282 & 2.016 .773 \\
\hline \multirow[t]{3}{*}{ Forasteros } & No residentes & 130.695 & 8.261 & 326.819 & 205 & 465.980 \\
\hline & Residentes & 194.477 & 390 & 7.685 & 1.475 & 204.027 \\
\hline & Total & 325.172 & 8.651 & 334.504 & 1.680 & 670.007 \\
\hline \multicolumn{2}{|l|}{ Total } & 749.232 & 20.975 & 1.872 .611 & 43.962 & 2.686 .780 \\
\hline \multicolumn{7}{|c|}{ Porcentaje } \\
\hline \multirow{3}{*}{ Vecinos } & Alicante & 40,3 & 57,5 & 80,6 & 18,6 & 68,2 \\
\hline & Partidas & 16,6 & 1,3 & 1,5 & 77,6 & 6,9 \\
\hline & Total & 56,9 & 58,8 & 82,1 & 96,2 & 75,1 \\
\hline \multirow[t]{3}{*}{ Forasteros } & No residentes & 17,4 & 39,3 & 17,5 & 0,5 & 17,3 \\
\hline & Residentes & 26,0 & 1,9 & 0,4 & 3,3 & 7,6 \\
\hline & Total & 43,4 & 41,2 & 17,9 & 3,8 & 24,9 \\
\hline
\end{tabular}

FUENTE: BOPA, 1852.

contribuyentes locales que pagaban menos de 100 reales suponían el 71 por 100 y aportaban el 19,9 por 100 de la contribución ${ }^{13}$.

Existía, por tanto, un desequilibrio entre el nivel de riqueza y la cuota satisfecha en el último tramo, el de los contribuyentes por debajo de los 50 reales. Desequilibrio que concuerda con otro señalado por Joaquín Azagra: «En los medianos y grandes propietarios el líquido resultante es levemente inferior al porcentaje de la riqueza poseída, produciéndose la situación inversa cuando se desciende en la escala de grupos hasta los más pequeños propietarios. A mayor porcentaje de rentas, menor líquido imponible y viceversa» ${ }^{14}$. Hay que tener en cuenta que la «responsabilidad

\footnotetext{
1) Millán (1999), p. 93.

it Azagra (1981), p. 271.
} 


\section{CUADRO 9}

Clasificación de los contribuyentes de 1852

\begin{tabular}{|c|c|c|c|c|c|c|}
\hline Tramos & Contribuyentes & $\%$ & Riqueza & $\%$ & Cuota & $\%$ \\
\hline $4.000-6.000 \ldots$ & 4 & 0,1 & 172.633 & 6,4 & 22.845 & 6,4 \\
\hline $2.000-4.000 \ldots$ & 12 & 0,3 & 243.776 & 9,1 & 32.643 & 9,1 \\
\hline $1.000-2.000 \ldots$ & 37 & 1,0 & 383.023 & 14,3 & 50.919 & 14,3 \\
\hline $100-1.000 \ldots \ldots \ldots$ & 607 & 15,7 & 1.401 .293 & 52,2 & 176.065 & 49,3 \\
\hline $50-100 \ldots \ldots \ldots \ldots$ & 333 & 8,6 & 184.297 & 6,9 & 24.539 & 6,9 \\
\hline Menos de $50 \ldots \ldots \ldots \ldots \ldots \ldots$ & 2.864 & 74,3 & 301.758 & 11,2 & 49.778 & 14,0 \\
\hline Total ..... & 3.857 & 100,0 & 2.686 .780 & 100,0 & 356.789 & 100,0 \\
\hline
\end{tabular}

FUENTE: BOPA, 1852.

colectiva constituyó un estímulo para la ocultación y el traslado de la carga fiscal ente los contribuyentes» ${ }^{15}$.

\section{LA RIQUEZA IMPONIBLE}

Pese a las dificultades y resistencias que tuvieron que salvar los empleados del Ministerio de Hacienda para poder hacer una evaluación aproximada de la riqueza rústica y urbana, la riqueza territorial de la provincia que había de servir de base para la determinación del cupo pasó de algo más de 48 millones a algo más de 55 , lo que supuso un aumento del 14,63 por 100 . El incremento más notable se produjo entre 1849 y 1851 , posiblemente para compensar la disminución de la riqueza imponible como consecuencia de la incorporación de Oliva y otros pueblos del partido de Pego a la provincia de Valencia. En cualquier caso se trataba de ajustar el cupo al 12 por 100 de la riqueza.

Madoz señaló en su Diccionario la importancia de las ocultaciones a la hora de precisar la magnitud de la riqueza provincial. En febrero de 1841 Manuel Cortina, ministro de Gobernación, ordenó la realización de una estadística de la riqueza que pudiera servir de base para un reparto más equitativo de las contribuciones. Los propietarios tendrían que presentar unas declaraciones que serían revisadas por una junta compuesta

${ }^{15}$ Vallejo (1997), p. 157. 
por el ayuntamiento y un número igual de mayores contribuyentes ${ }^{16}$. Esa comisión de notabilidades fijó el volumen de riqueza de la provincia en una cifra ciertamente ridícula: 7.721 .273 reales, de los que 5.268 .548 reales -el 68,2 por 100 - correspondían a la riqueza territorial, a los que habría que añadir 64.455 reales el 0,8 por 100 - por riqueza pecuaria y 1.367 .811 reales por urbana -el 17,7 por 100 - El resto de la riqueza imponible lo aportaba la industria y el comercio. Si relacionamos esas cifras con los 250.590 habitantes que declara la junta como población de la provincia, resulta una renta per cápita de 3,2 maravedíes diarios, claramente insuficiente para que la población pudiera subsistir ${ }^{17}$. Madoz achacó la poca fiabilidad de la estadística al hecho de que fuera encargada por el Ministerio de Gobernación, y no por el de Hacienda, cuyos funcionarios, además, sólo disponían de cuatro días para revisar los datos ${ }^{18}$. En junio de 1842 se puso en marcha una nueva operación estadística, esta vez dirigida por el Ministerio de Hacienda, las Matriculas Catastrales de Calatrava, que pretendían servir de base a un nuevo proyecto de contribución directa presentado por Surrá y Rull. Aunque la evaluación de la riqueza se dejó en manos de técnicos expertos, las matrículas no pasaron de ser «estimaciones sin ninguna base objetiva» ${ }^{19}$. Esta evaluación fijó la riqueza imponible en más de 35 millones de reales, pero mientras que la riqueza urbana seguía participando con un 17 por 100 en el total (6.095.538 reales), la riqueza territorial aportaba solamente el 44 por 100 -algo más de 15,6 millones-, su participación en el total de la riqueza imponible había descendido con respecto a la evaluación de $1841^{20}$. Pese al espectacular aumento de la riqueza, el fraude seguía siendo elevado, las cifras de 1842 resultaban increíbles, y el volumen de exportación de productos agrarios desmentía esos datos. El nuevo sistema tributario elevó de forma sensible la riqueza imponible, pero las sucesivas subidas experimentadas a lo largo de la década significaban que todavía quedaba margen para una evaluación más ajustada a la realidad (cuadro 10), lo que parece sugerir que la riqueza imponible no se correspondía con la riqueza real.

${ }^{16}$ Pro (1992), p. 61.

17 Madoz (1995), pp. 104-107. Lo reducido de estas cifras hace comentar irónicamente a Madoz: «Contra nuestra opinión anteriormente manifestada de que la laboriosidad de los españoles ha extendido el dominio agrícola, se presenta el parecer de las autoridades y demás ciudadanos distinguidos que fijaron en el año de 1841, después de varias operaciones, la riqueza imponible de la provincia de Alicante», p. 112.

${ }^{1 *}$ Pro (1992), p. 65.

19 Pro (1992), p. 67.

${ }^{20}$ Madoz (1995), pp. 108 y 115. 
CUADRO 10

Riqueza imponible

\begin{tabular}{|c|c|c|}
\hline$A \bar{o} o$ & Reales & Variación (\%) \\
\hline $1849 \ldots \ldots \ldots \ldots . . . . . . . .$. & 48.178 .887 & \\
\hline $1851 \ldots \ldots \ldots \ldots \ldots$ & 54.908 .870 & 13,96 \\
\hline $1852 \ldots \ldots \ldots \ldots \ldots$ & 55.793 .407 & 1,61 \\
\hline $1854 \ldots \ldots \ldots \ldots \ldots$ & 55.229 .700 & $-1,01$ \\
\hline
\end{tabular}

FUENTE: Díaz (1998), p. 393.

\section{CUADRO 11}

Estructura de la riqueza territorial en 1849

\begin{tabular}{|c|c|c|c|c|}
\hline Reales & Municipios & Riqueza imponible & $\%$ & Cuota en \%* \\
\hline 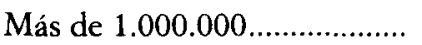 & 11 & 22.080 .681 & 45,83 & 44,11 \\
\hline 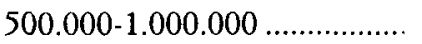 & 13 & 8.983 .589 & 18,64 & 18,58 \\
\hline $400.000-500.000 \ldots \ldots \ldots \ldots \ldots \ldots$ & 8 & 3.682 .262 & 7,64 & 7,81 \\
\hline $300.000-400.000 \ldots \ldots \ldots \ldots \ldots \ldots$ & 7 & 2.021 .942 & 4,20 & 5,15 \\
\hline $200.000-300.000 \ldots \ldots \ldots \ldots \ldots \ldots$ & 13 & 3.306 .775 & 6,86 & 7,05 \\
\hline 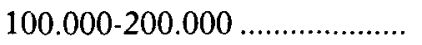 & 35 & 4.592 .557 & 9,53 & 10,09 \\
\hline Menos de $100.000 \ldots \ldots \ldots \ldots \ldots$ & 55 & 3.510 .989 & 7,09 & 7,21 \\
\hline Total ....... & 142 & 48.178 .887 & 100,00 & 100,00 \\
\hline
\end{tabular}

* La cuota incluye el cupo más los recargos para gastos municipales, provinciales, fondo supletorio y gastos de cobranza.

FUENTE: $B O P A$ de 1 de diciembre de 1848 .

Según la contribución de inmuebles de 1849 (cuadro 11) había 11 municipios cuya riqueza imponible superaba el millón de reales, situados: dos, en los partidos de Denia y Novelda, y uno en los de Alcoy, Alicante, Cocentaina, Elche, Orihuela, Pego y Villena, que acumulaban en conjunto más del 45 por 100 de la riqueza territorial. Trece pueblos tenían un nivel de riqueza comprendido entre el medio millón y el millón de reales, que en conjunto concentraban algo más del 18 por 100 de la riqueza. Otros 63 municipios, con un nivel de riqueza comprendido entre los 400.000 y los 100.000 reales, reunían cerca del 30 por 100 de la riqueza, acumularido el resto cerca del 7 por 100 . El mayor grado de polarización de la riqueza 
se daba en el norte de la provincia - Callosa d'En Sarrià, Cocentaina, Denia, Pego- y en la Vega Baja - Dolores y Orihuela ${ }^{21}$ - Por otro lado, conviene señalar que no hay una correlación exacta entre la cuota que pagaban los pueblos y su nivel de riqueza, debido a que los ayuntamientos aplicaban recargos distintos.

\section{LA INJUSTICIA FISCAL. RESISTENCIAS Y PROTESTAS}

La reforma fiscal de 1845 marca la implantación en España de la Hacienda liberal, pero no por ello hay que olvidar que se trató de una reforma injusta —aunque no más que el cuadro impositivo anterior-, debido en gran parte a la forma en que se gestionó la contribución de inmuebles ${ }^{22}$. Pueblos y particulares se sentían agraviados por un sistema fiscal que, careciendo de una estadística fiable de la riqueza territorial, permitía a las oligarquías locales realizar los repartos de los cupos, que con frecuencia no guardaban una exacta relación con los niveles de riqueza, lo que desató muy pronto las críticas hacia el sistema tributario ${ }^{23}$. Unas críticas que obedecían a distintas motivaciones y que se tradujeron en la resistencia de los contribuyentes a declarar la riqueza imponible, cuya evaluación quedó en manos de la oligarquía; en el rechazo al repartimiento de los cupos y de las cuotas individuales; y en las protestas por el tratamiento discriminatorio de que eran objeto las reclamaciones de agravio. Se trataba de críticas que traslucían la arbitrariedad con que se gestionaba la contribución.

\subsection{La evaluación de la riqueza, en manos de la oligarquía}

La estadística de riqueza la elaboraban las juntas periciales o las comisiones de evaluación, compuestas por los mayores contribuyentes, nombrados por los ayuntamientos y los intendentes ${ }^{24}$. Por lo que respecta a la ciudad de Alicante y su término, las comisiones estuvieron formadas por lo más granado de la burguesía local, y por los representantes -apoderados - de los grandes propietarios forasteros ${ }^{25}$ (cuadro 12). La presencia de estos últimos en las

${ }^{21}$ Díaz (1998), pp. 247-260 y 393.

${ }^{22}$ Comin (1988 y 1994), Fontana (1977) y Pro (1994).

${ }^{23}$ En una fecha tan temprana como febrero de 1846 la Sociedad Mercantil Matritense solicitó al gobierno la revisión del plan de Mon, Bahamonde y Toro (1978), p. 196.

${ }^{24}$ Pro (1992), pp. 74-98; Segura (1988).

${ }^{25}$ En uno u otro momento formaron parte de las comisiones de evaluación y repar- 


\section{CUADRO 12}

Miembros de las comisiones de evaluación y peritos repartidores de la contribución territorial designados por el Ayuntamiento de Alicante en 1849

\begin{tabular}{|c|c|c|}
\hline Perito & $\begin{array}{l}\text { Contribución } 1847 \\
\text { (reales) }\end{array}$ & $\begin{array}{c}\text { Contribución } 1849 \\
\text { (reales) }\end{array}$ \\
\hline 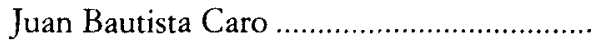 & 3.239 & 4.003 \\
\hline 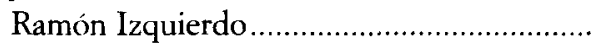 & 2.297 & 3.117 \\
\hline 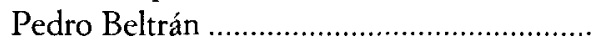 & 2.349 & 3.080 \\
\hline 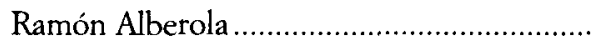 & 1.490 & 2.902 \\
\hline 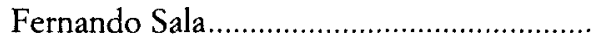 & 2.313 & 2.408 \\
\hline José Gabriel Amérigo ............... & & 2.393 \\
\hline 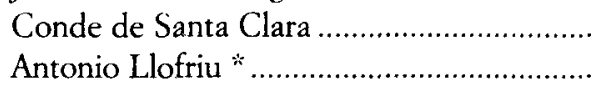 & 1.569 & 1.861 \\
\hline 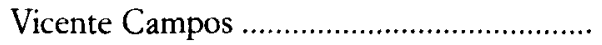 & 1.127 & \\
\hline
\end{tabular}

Fuentes: AMA (Archivo Municipal de Alicante), Libro de Cabildos, 9 de octubre de 1849 y 1 de noviembre de 1849, y AMA, armario 2, caja 13-II, legajo 51.

* Apoderado del marqués de Arneva.

comisiones de evaluación pretendía evitar que los ayuntamientos sobrecargaran a los hacendados forasteros, con menos posibilidades de ocultar sus bienes que los vecinos, tal y como reconocía el propio gobierno ${ }^{26}$. Para evitar estos abusos, la Diputación advertía a los ayuntamientos en 1848 que no se podía imponer una cuota superior al 12 por 100 del producto líquido de sus bienes ni a los propietarios forasteros ni a los bienes nacionales ${ }^{27}$, cuota que ya se había extendido a todos los propietarios por Real Orden de 3 de septiembre de $1847^{28}$. Pero quienes no estaban representados en estas juntas eran los pequeños y medianos propietarios, de modo que no

timiento personas con importantes intereses económicos en la Huerta de Alicante y en el comercio: Antonio Sereix, Juan Bautista Lafora, Tomás España, José Enríquez de Navarra, los apoderados del conde de Soto-Ameno, del conde de Casa-Rojas, de la condesa de Almodóvar, del marqués de Arneva, José Bas; Díaz (1998), p. 394.

${ }^{26}$ BOPA de 23 y 25 de julio de 1849 . Estos abusos eran la consecuencia de las atribuciones que la legislación otorgaba a las diputaciones y ayuntamientos para fijar el cupo, lo que, según Artola (1986), «constituye un ejemplo de los efectos que se siguen de la capacidad de las autoridades más próximas al ciudadano para tratarlo de forma tan arbitraria como el poder central», p. 243.

27 BOPA de 6 de diciembre de 1848.

${ }^{28}$ Pro (1992), pp. 78-79. 
se pudo equilibrar el peso de los grandes contribuyentes en las mismas, a diferencia de lo que sucedió en otros lugares ${ }^{29}$.

Las juntas evaluadoras trabajaban con las declaraciones juradas presentadas por los propietarios, que no tenían demasiado interés en declarar sus propiedades, por lo que había que ampliar los plazos de presentación y recurrir a medidas coactivas. En 1846 el alcalde de Alicante, Miguel Pascual de Bonanza, uno de los principales propietarios de la Huerta, denunciaba que la junta pericial de evaluación y repartimiento no adelantaba en sus trabajos, debido a «la falta de presentación de las relaciones juradas que deben formar los propietarios de fincas rústicas y urbanas, los inquilinos, arrendadores y ganaderos», irresponsabilidad en la que incurrían «cuasi todos los vecinos de esta capital y su término», impidiendo así que hubiera «una mayor equidad en los repartimientos» tanto individuales como generales ${ }^{30}$. Un año más tarde el alcalde llegó a amenazar a los propietarios y arrendatarios que no hubieran formalizado las relaciones de riqueza en el plazo correspondiente con una multa equivalente a la cuarta parte de su renta ${ }^{31}$. En 1850 el jefe de la comisión de estadística de la provincia y presidente de la junta de evaluación y repartimiento decidió comprobar sobre el terreno la veracidad de las relaciones de riqueza presentadas por los propietarios, no sin antes darles la oportunidad de rectificar sus declaraciones, añadiendo la riqueza que hubieran omitido ${ }^{32}$. La inspección comenzó por los pueblos que habían presentado reclamaciones de agravio - medida encaminada a desanimar a otros pueblos a reclamar-, y de ella resultó una multa a Benijófar, en el bajo Segura, por presentar una masa imponible «desfigurada en extremo» ${ }^{33}$. Pese a las advertencias de las autoridades, la falsedad era consentida por las juntas periciales y por los ayuntamientos, instituciones ambas copadas por los propietarios. Resultaban así unas declaraciones que reducían la superficie cultivada, inflaban los gastos y presentaban una masa imponible alejada de la realidad, hecho que la comisión de estadística de la provincia y la administración de contribuciones directas atribuian a la parcialidad y mala fe con que actuaban las corporaciones locales y las juntas evaluadoras.

En este sentido, el comisionado regio de agricultura de la provincia de Alicante, Joaquín Roca de Togores, un cualificado representante de

${ }^{24}$ En algunos municipios de las comarcas vitícolas catalanas era importante la presencia de pequeños propietarios y rabassers en las juntas periciales, Colomé (1997).

30 BOPA de 10 de febrero de 1846 y 15 de febrero de 1847 .

"BOPA de 28 de abril de 1847.

32 BOPA de 3 de junio de 1850.

${ }^{33}$ BOPA de 24 de junio de 1850. 
la burguesía agraria, consideraba como uno de los objetivos fundamentales de un buen gobierno el establecer un sistema equitativo de exacción y reparto de las contribuciones, que no podía quedar en manos de los ayuntamientos, «pues las pasiones y enemistades que generalmente dominan en las localidades pequeñas producen injusticias en los repartos», y proponía poner la recaudación en manos de cobradores sin sueldo fijo, que percibirían un porcentaje sobre la cantidad recaudada. La base de la justicia fiscal, insistía, era la formación de la estadística de la riqueza realizada por comisiones mixtas de técnicos agrónomos y «vecinos prácticos», cuya presencia se justificaba por la necesidad de vencer la desconfianza de los pueblos hacia los agentes del gobierno ${ }^{34}$. Esta desconfianza se traducía en la resistencia al pago del impuesto. Como muestra el cuadro 13, entre 1849 y 1852 la Diputación recaudó por contribución de inmuebles para financiar los gastos provinciales más de tres millones de reales, de los que casi la tercera parte correspondía a repartos de años anteriores ${ }^{35}$.

Para hacer más efectiva la tarea evaluatoria, en 1850 se asoció a la comisión de estadística provincial un equipo de técnicos con la misión de ayudar a las corporaciones locales a evaluar la riqueza y evitar la ocul-

\section{CUADRO 13}

Cantidades recaudadas por la Diputación por contribución territorial para gastos provinciales (1849-1852)

\begin{tabular}{|c|c|c|c|}
\hline Año & Recaudación & $\begin{array}{l}\text { Cantidad comrespondiente } \\
\text { a ejercicios anteriores }\end{array}$ & $\%$ \\
\hline 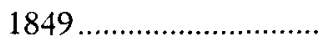 & 638.956 & 181.889 & 28,5 \\
\hline 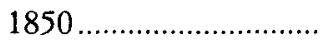 & 1.343 .243 & 684.343 & 50,9 \\
\hline $1851 \ldots \ldots \ldots \ldots \ldots \ldots \ldots \ldots$ & 641.116 & 137.187 & 21,4 \\
\hline $1852 \ldots \ldots \ldots \ldots \ldots \ldots \ldots \ldots$ & 514.954 & 31.509 & 6,1 \\
\hline$\ldots \ldots \ldots \ldots \ldots \ldots$ & 3.138 .269 & 1.034 .928 & 33,0 \\
\hline
\end{tabular}

FuENTE: Archivo Diputación Provincial (ADPA), Contabilidad provincial, legajo 532 (12.144).

${ }^{34}$ Roca de Togores (1849), pp. 93-94.

35 ADPA, Contabilidad provincial, legajo 532 (12.144). La elevada cifra de 1850 se debe a que ingresaron en las arcas provinciales 441.552 reales del fondo supletorio de 1848 y 1849 para financiar obras públicas. En 1852 todavía quedaban pendientes de cobro 12.822 reales del reparto de 1847 . 
tación ${ }^{36}$. Sin embargo, estas comisiones gravaron las haciendas locales - sus gastos corrían a cargo de los ayuntamientos- y no cumplieron con eficacia su cometido, dado que no contaron con la colaboración ni de los ayuntamientos, ni de los propietarios, con lo que las cartillas de evaluación continuaron suministrando información errónea. Así lo reconocía en 1853 el gobernador civil, quien ordenaba a los alcaldes que colaboraran con las comisiones evaluadoras, pues los datos presentados hasta entonces contenían numerosos errores ${ }^{37}$. Y es que la ocultación en la contribución territorial no era «un fallo del sistema, sino un elemento fundamental de él» ${ }^{38}$.

\subsection{Repartos sin estadística. El rechazo a los cupos}

Basado en esta información errónea, el reparto de los cupos daba pie a arbitrariedades e injusticias que eran reconocidas, aunque no corregidas, por los ayuntamientos y la Diputación, la cual justificó reiteradamente las desigualdades en la asignación de los cupos a los pueblos por la inexistencia de una estadística de la riqueza fiable. No resulta extraño, pues, que algunos diputados provinciales se abstuvieran cuando se aprobaban unos repartos que consideraban perjudiciales para los partidos que representaban, y en los cuales normalmente ellos mismos poseían importantes propiedades, pues, según la Ley de Organización de las Diputaciones provinciales de 8 de enero de 1845, para poder ser diputado provincial se requería, entre otras cosas, disfrutar de una renta anual procedente de bienes propios superior a 8.000 reales o pagar 500 reales por contribuciones directas, y residir en la provincia o tener propiedades en ésta por las que se pagaran 1.000 reales de contribución. Por lo tanto, los diputados provinciales pertenecían a las élites económicas y profesionales, procedentes de un reducido grupo de propietarios y abogados, soporte social del moderantismo politico ${ }^{39}$, que anteponían los intereses de sus representados, de sus votantes, a los intereses generales de la provincia. El reparto de 1850 fue aprobado con los votos en contra de los diputados de Elche y Orihuela, al de 1851 se opusieron los representantes de Denia y Monóvar, con el de 1852 mostraron su disconformidad los diputados de Villena, Villayojosa y Monóvar,

\footnotetext{
36 BOPA de 14 de agosto de 1850 .

37 BOPA de 27 de julio de 1853.

38 Fontana (1977), p. 339.

${ }^{39}$ Díaz (1998), pp. 131-144.
} 
y el de 1853, efectuado por la Administración de contribuciones directas, encontró la oposición del pleno de la Diputación, aunque finalmente acabó aceptándolo ${ }^{40}$.

La Diputación moderada hizo poco por corregir la falta de datos estadísticos fiables para distribuir el cupo. Por lo tanto, si la asignación de éstos no se basaba en la estadística, cabe pensar que eran razones de tipo político, de relaciones personales, las que mediaban a la hora de efectuar los repartos ${ }^{41}$. Cuando en 1845 entró en vigor la contribución de inmuebles, cultivo y ganadería, la Diputación, aunque con algunas modificaciones, propuso que se tomara como base el reparto de las contribuciones de equivalente, paja y utensilios y culto y clero, introduciendo algunas modificaciones que recargaban o aliviaban algunos pueblos. Los partidos de Monóvar, Villajoyosa, Alcoy y Villena sufrieron recargo, los tres primeros porque su cupo era bajo, y el cuarto porque iba a dejar de pagar la contribución de rentas provinciales, por la que estaba exento del equivalente. La capital de la provincia también fue recargada para compensar la rebaja que se hacía al pueblo de San Juan, con lo que el monto total del partido no varió. Se redujo el cupo a los partidos de Jijona, Elche, Dolores y Novelda, aunque la Diputación reconoció la necesidad de «ser parcos no tanto por la falta de datos, cuanto por evitar en lo que razonablemente sea posible la rivalidad de quejas de los demás» ${ }^{42}$. Se estableció así el principio de sucesivos repartos, que apenas experimentarian variación durante la Década Moderada, y que recogía el defecto de base reconocido por la propia Diputación al efectuar la asignación de los cupos el año anterior ${ }^{43}$.

Efectivamente, en marzo de 1844 , cuando se planteó el reparto de contribuciones de cuota fija, la Diputación se mostró convencida de la urgente necesidad de modificar los cupos, para llegar a «una prudente nivelación entre determinados partidos que ofrecian a la vista una desproporción enormisima», pero reconoció que resultaba peligroso introducir cambios

${ }^{40}$ Ibidem, pp. 395-396.

41 Pro (1995) constata este fenómeno para la provincia de Cádiz.

42 ADPA, Libro de Actas, 19 de agosto de 1845.

43 ADPA, Libro de Actas, 24 de noviembre de 1844. En esta sesión «se habló de las causas que han impedido la reunión de datos estadísticos, de la imposibilidad de adquirir en tan corto tiempo los absolutamente indispensables para hacer alguna ligera reforma de los cupos antiguos, a no ser que se efectuara por la convicción oral expuesta siempre a errores muy trascendentales en esta materia; o por la base de población, que sobre reconocerse en ella defectos bastante considerables, no puede tratarse sino como un dato auxiliatorio para apreciar la riqueza de los pueblos». 
ante la falta de datos. En consecuencia decidió no alterar el reparto; comenzar la formación de la estadística de la riqueza provincial y que se tuviera en cuenta para el año próximo, aunque sólo fueran los datos parciales; e indemnizar en el reparto de 1845 a los pueblos perjudicados en el de $1844^{44}$. Para poder rectificar los repartimientos, en noviembre de ese mismo año la Diputación acordó exigir del registro de hipotecas una certificación, con indicación del precio, de las tres primeras y tres últimas escrituras de venta de tierras que hubieran tenido lugar en cada pueblo entre 1840 y 1844 ; pedir una certificación notarial que expresara lo mismo con respecto a las tierras cedidas en arriendo; demandar del secretario de la junta de aguas otra certificación de la superficie de regadío existente en el término municipal; los secretarios de los ayuntamientos tenían que informar del número de tahúllas incluidas en el padrón de contribución, así como del número y clase de fábricas y carruajes y de la población del término; finalmente, los diputados de cada partido debían convencer a las autoridades locales y personas influyentes de que el conocimiento de estos datos por la Diputación no amenazaba los intereses de los propietarios, pues no se iba a hacer uso de ellos hasta que la información hubiera sido contrastada por otros diputados y se tuviera «un convencimiento seguro de que en todas partes se ha obrado con buena fe, $y$ con exactitud». Estas esperanzas tuvieron que verse decepcionadas, pues en mayo de 1845 el jefe político autorizó al diputado por Orihuela Andrés Rebagliato - una de las principales figuras del moderantismo en la provincia e importante propietario ${ }^{45}$ - a imponer hasta 1.000 reales de multa a cualquier persona o corporación que se mostrase morosa en aportar los datos necesarios para formar la estadística del partido ${ }^{46}$. Aunque ese año se introdujeron algunas modificaciones en el reparto de los cupos, la situación de agravio continuó. En 1848 el jefe político aceptaba resignadamente las dificultades que se oponían a la formación de la estadística de la riqueza, «para que fuese el justo nivelador de los impuestos públicos», y se lamentaba ingenuamente ante el inspector de la Administración civil del Distrito de que «ni las palabras de honor leal y caballerosamente empeñadas, ni las promesas hechas y garantías dadas de guardar silencio..., nada ha bastado para obtener los estados que reclamaba» ${ }^{47}$. El nuevo sistema tributario heredaba de épocas anteriores un deficiente conocimiento de la riqueza

\footnotetext{
+4 lbidem, 31 de marzo de 1844

t5 Díaz (1998) y Millán (1999).

to Guerra (1848).

47 Guerra (1848).
} 
imponible, la falta de estadística sería «el principal escollo con el que iba a tropezar la puesta en marcha de la nueva contribución» ${ }^{48}$. Los obstáculos para un conocimiento real de la misma persistieron, y la falta de datos estadísticos sólidos continuó. Todo ello contradecía el supuesto interés de la oligarquía en averiguar la riqueza real de la provincia. Por lo tanto, no podemos creer sinceras las proclamas de las autoridades locales reclamando una mayor veracidad en las declaraciones de riqueza.

Otra cosa era la actitud de los intendentes y funcionarios de Hacienda, más interesados en vencer la resistencia de unos contribuyentes reticentes a la contribución directa y habituados a la ocultación, de ahí la campaña de apremios, especialmente intensa entre 1844 y 1846 , implicando a los alcaldes en la misma, llegando alguno a amenazar con ejecutar «la venta de bienes para hacer constar la solvencia o insolvencia de los contribuyentes y cubrir además la responsabilidad del Ayuntamiento gravemente comprometida» ${ }^{49}$. La presión fue tal que el propio jefe político pidió al intendente que moderara los apremios contra los pueblos ${ }^{50}$.

\subsection{Las reclamaciones. Un tratamiento discriminatorio}

Pese a que la Diputación mostraba su comprensión hacia las quejas y protestas y reconocía la injusticia de los repartos ${ }^{51}$, el trato dado a las reclamaciones de los pueblos era discriminatorio, y es que muchas de sus decisiones en materia de hacienda estaban mediatizadas por el peso político de los municipios. Así, mientras que las reclamaciones presentadas por Benisa y Senija en 1848, o las de Denia, Tibi, Novelda, Sella, Agost, Elda, Jijona, Monóvar, Pinoso y Petrel en 1849 fueron rechazadas por la Diputación y el intendente, la solicitud presentada por el Ayuntamiento de Alicante y varios propietarios pidiendo la condonación de la contribución por la sequía fue apoyada por la corporación provincial, reconociendo que era público y notorio «el abatimiento y esterilidad de sus campos» ${ }^{52}$. Cier-

${ }^{48}$ Pérez Picazo (1998), p. 128.

49 BOPA de 8 de julio de 1845. La resistencia al fisco no era cosa exclusiva de los contribuyentes en apuros. En 1845 el barón de Finestrat adeudaba impuestos por varios conceptos, principalmente por el equivalente de 1844, por lo que el alcalde le amenazó con embargar los «efectos o frutos de su pertenencia de más fácil salida» para saldar la deuda. Díaz (1998), p. 75.

50 BOPA de 20 de enero de 1846.

s1 ADPA, Libro de Actas, 16 de octubre de 1847. La Diputación seguía reconociendo el «desnivel con que contribuyen algunos pueblos».

"2 Díaz (1997). Las reclamaciones de Benisa, Senija, Tibi y Denia también se basaban en desastres climatológicos, p. 569. 
tamente, la situación de la provincia era lamentable, por lo que la Diputación y el gobernador habían solicitado al ejecutivo en repetidas ocasiones la rebaja del cupo, buscando la mediación de los representantes de la provincia en el Congreso. La oligarquía consideraba que la provincia estaba sobrecargada por contribución territorial y sometida a presiones excesivas por parte del fisco ${ }^{53}$. Entre 1850 y 1854 la riqueza evaluada en el conjunto del país había aumentado un 8,4 por 100 , mientras que en la provincia de Alicante, entre 1849 y 1854 , lo había hecho en un 14,6 por $100^{54}$, llegando a representar la riqueza imponible provincial entre el 2,2 y el 2,6 por 100 de la riqueza imponible nacional, aportando el 2,2 por 100 del cupo de 300 millones de reales anuales fijados por el gobierno. Además, el tipo que gravaba la riqueza provincial estaba ligeramente por encima de la media nacional (cuadro 14). Eran argumentos que la Diputación podía esgrimir ante el gobierno, que finalmente sólo accedió a rebajar la décima parte del cupo de $1851^{55}$.

La Diputación y las oficinas de Hacienda renunciaban a la estadística para revisar los cupos, lo que daba pie a la arbitrariedad, «que es posible cuando no existen estadísticas» ${ }^{56}$. Las reclamaciones de los pueblos evi-

\section{CUADRO 14}

Tipo teórico sobre la riqueza imponible

\begin{tabular}{ccc}
\hline Año & España & Alicante \\
\hline $1849 \ldots \ldots \ldots \ldots$. & & 13,7 \\
$1850 \ldots \ldots \ldots \ldots$. & 12,2 & \\
$1851 \ldots \ldots \ldots \ldots$. & 12,6 & 12,0 \\
$1852 \ldots \ldots \ldots \ldots$. & 11,2 & 11,8 \\
$1853 \ldots \ldots \ldots \ldots$. & 11,2 & \\
$1854 \ldots \ldots \ldots \ldots$. & 11,2 & 12,0 \\
\hline
\end{tabular}

FuENTES: Pro (1992), p. 90. Para la provincia de Alicante, Díaz (1998), p. 393.

${ }^{3}$ La Diputación de Barcelona también protestó de forma reiterada la cuota asignada por el Ministerio de Hacienda a la provincia, ya que se situaba por encima del 12 por 100 de la base imponible. Asimismo, se sentía agraviada con respecto a otras provincias de agricultura más rica, como Valencia o Sevilla. Fradera, pp. 129-131.

s4 Los datos para el conjunto del país en Pro (1992), p. 90. Para la provincia de Alicante, Díaz (1998), p. 393.

"5íaz (1998), pp. 396-397.

${ }^{56}$ El Ministerio de Hacienda había suprimido en 1847 la Comisión Central de Esta- 
denciaban que el nuevo sistema tributario no había corregido las desigualdades, y que persistía - o se acentuaba para algunos- - una situación que criticaron con rotundidad en 1851 los ayuntamientos de Elda, Pinoso, Salinas y Pedreguer. Estos municipios denunciaron el incremento continuado del cupo desde 1845, así como el aumento - a su juicio ficticiode la riqueza imponible. Se lamentaban de la arbitrariedad de las juntas periciales y de la Diputación al fijar los cupos y evaluar la riqueza, para poder acomodarla al gravamen del 12 por 100 que representaba el cupo, de manera que resultaban unas cantidades desproporcionadas que no podían ser satisfechas «sin vender los labradores sus muebles para pagar tan enormes sumas», y pedían que se elaborase un padrón de riqueza sobre bases más equitativas ${ }^{57}$. La denuncia de estas corporaciones reflejaba la desigualdad y el desequilibrio con que se dejaba sentir la fiscalidad sobre los municipios. Si consideramos conjuntamente las contribuciones de cuota fija y la parte de la contribución de culto y clero que gravaba la riqueza territorial y pecuaria, resulta que los bienes inmuebles y las actividades agrarias tributaban, antes de ponerse en marcha la reforma de Mon, 3.902.629 reales en concepto de equivalente, paja y utensilios y 1.624 .465 reales por la parte territorial de la contribución de culto y clero, lo que sumaba 5.527.094 reales (cuadro 15). Esta cifra está relativamente cerca del cupo de 6.100 .000 reales que el gobierno asignó a la provincia en 1846 por contribución de inmuebles ${ }^{58}$. Se confirma la validez del criterio de equivalencia entre impuestos asimilables antes y después de la reforma de Mon propuesto por Fontana, para quien la contribución de inmuebles «no era otra cosa que la consolidación de las viejas contribuciones de cuota fija y la universalización de un sistema de reparto basado en un catastro de riqueza, tal como se venía practicando en la Corona de Aragón» ${ }^{59}$, lo que significaba atenuar el carácter innovador de la mencionada contribución. Francisco Comín también se muestra de acuerdo con este criterio de equivalencia, pues los 227 millones que sumaban en 1843 las contribuciones de cuota fija se aproximaban más a los 300 millones de la contribución de inmuebles de 1845 que los 118 millones «que suponían los tributos que legalmente se refundieron en la contribución territorial», y todavía la aproximación hubiera sido mayor de haberse añadido los 66,4

dística y las oficinas de estadística se incorporaron a la Dirección de contribuciones, Vallejo (1997), p. 153.

${ }^{57}$ ADPA, Fomento, legajo 116.

5* BOPA de 14 de julio de 1846.

59 Fontana (1977), p. 252. 


\section{CUADRO 15}

Contribución territorial en 1845 (reales)

\begin{tabular}{|c|c|c|c|}
\hline Partido & $\begin{array}{c}\text { Equivalente y paja } \\
\text { y utensilios }\end{array}$ & Culto y clero & Total \\
\hline Elche.... & 417.651 & 170.947 & 588.598 \\
\hline Pego ........... & 402.327 & 164.560 & 566.867 \\
\hline 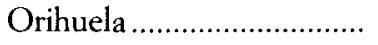 & 397.490 & 162.604 & 560.194 \\
\hline 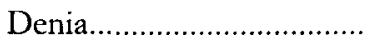 & 349.194 & 142.761 & 491.955 \\
\hline 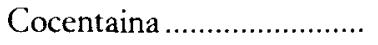 & 324.445 & 132.757 & 457.202 \\
\hline 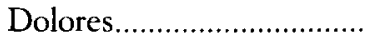 & 304.528 & 124.830 & 429.358 \\
\hline 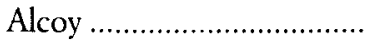 & 291.887 & 119.539 & 411.418 \\
\hline 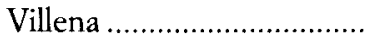 & 275.311 & 91.171 & 366.482 \\
\hline 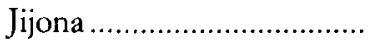 & 257.444 & 105.298 & 362.742 \\
\hline Alicante ................................ & 231.923 & 141.162 & 373.085 \\
\hline 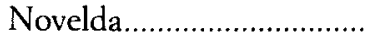 & 230.394 & 94.239 & 324.633 \\
\hline C. d'En Sarrià ....................... & 220.094 & 89.986 & 310.080 \\
\hline Monóvar................................ & 105.999 & 46.346 & 152.345 \\
\hline Villajoyosa ......................... & 93.940 & 38.275 & 132.215 \\
\hline Total... & 3.902 .629 & 1.624 .465 & 5.527 .094 \\
\hline
\end{tabular}

FutNTE: Díaz (1998), p. 398.

millones «a que hubiera ascendido la contribución de culto y clero» en $1843^{60}$.

Como muestra el cuadro 16, la implantación de la nueva figura tributaria supuso un incremento del cupo del 19,2 por 100 en 1850 y del 19,9 por 100 en 1853. Ahora bien, ese aumento no se repartió de forma igualitaria entre los municipios. La nueva contribución supuso una reducción del cupo para el partido de Pego del orden del 60 por 100, debido a la segregación de Oliva y su comarca, que se incorporaron a la provincia de Valencia. En Orihuela, Elche y Alicante - los tres municipios con mayor peso político de la provincia-, tras una subida en 1850 de entre el 11 y el 27 por 100 , en 1853 el incremento se queda en el 13 por 100, llegando Elche a situarse por debajo del nivel de 1845 . Tal vez no sea ajeno a esta trayectoria el hecho de que éste era el distrito en el que Mariano Roca de Togores - una importante figura del moderantismo que fue varias veces

(4) Comin (1988), p. 143. 


\section{CUADRO 16}

Incremento del cupo por territorial

$(1845=100)$

\begin{tabular}{|c|c|c|}
\hline Partido & 1850 & 1853 \\
\hline illajoyosa. & 163,9 & 174,4 \\
\hline Monóvar... & 194,7 & 172,44 \\
\hline Dolores....... & 122,9 & 149,67 \\
\hline Denia ........................... & 128,0 & 142,84 \\
\hline C. d'En Sarrià . & 126,9 & 139,19 \\
\hline Aloy. & 129,3 & 130,40 \\
\hline ......... & 125,5 & 127,12 \\
\hline Novelda.. & 125,3 & 120,51 \\
\hline Jijo & 119,4 & 120,44 \\
\hline Ville & 116,9 & 119,27 \\
\hline Orit & 123,1 & 113,64 \\
\hline ......... & 127,8 & 113,41 \\
\hline ................. & 111,9 & 95,12 \\
\hline 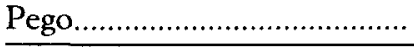 & 42,7 & 62,48 \\
\hline Media & 119,21 & 119,90 \\
\hline
\end{tabular}

FUENTE: BOPA de 14 de abril de 1844,14 de diciembre de 1844,16 de noviembre de 1849 y 12 de noviembre de 1852 .

ministro de Comercio, Instrucción y Obras Públicas y de Marina- disponía de una sólida red clientelar que le permitió ser elegido diputado en los sucesivos comicios celebrados durante la Década Moderada ${ }^{61}$. Alcoy, Cocentaina, Novelda y Jijona aumentan su cupo entre un 20 y un 30 por 100, mientras que Denia, Callosa d'En Sarrià y Dolores lo hicieron entre el 40 y el 50 por 100 . Finalmente, Villajoyosa y Monóvar experimentaron un salto espectacular, que en el caso de Monóvar se situó por encima del 90 por 100 para 1850 , aunque en 1853 ambos partidos descendieron a niveles que rondaban el 73 por 100 .

El análisis del cupo por habitante confirma lo anteriormente dicho (cuadro 17). En 1853 el cupo por habitante había subido cerca del 13 por

${ }^{61}$ Díaz (1998), pp. 199-200. Mariano Roca de Togores, que recibirá el título de marqués de Molins en 1848, fue elegido por el distrito de Elche en $1844,1846,1850$ y 1853 , casi siempre con el 100 por 100 de los votos. 


\section{CUADRO 17}

Cupo por babitante (reales/habitante)

\begin{tabular}{|c|c|c|c|}
\hline \multirow{2}{*}{ Partido } & \multirow{2}{*}{$\frac{1845}{\text { Reales/bab. }}$} & \multicolumn{2}{|c|}{1853} \\
\hline & & Reales/bab. & Variación (\%) \\
\hline Villajoyosa.... & 7,12 & 12,62 & 77,25 \\
\hline 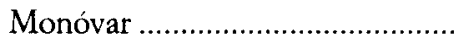 & 8,92 & 15,43 & 72,98 \\
\hline 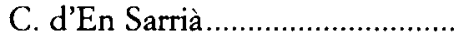 & 11,07 & 17,15 & 54,92 \\
\hline 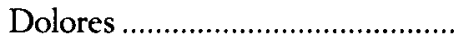 & 20,21 & 31,30 & 54,87 \\
\hline 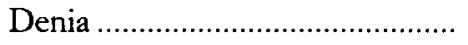 & 24,56 & 35,10 & 42,92 \\
\hline Alcoy & 20,39 & 26,30 & 28,98 \\
\hline 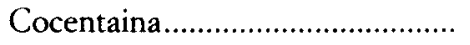 & 22,00 & 27,65 & 25,68 \\
\hline Novelda ..... & 19,95 & 21,30 & 25,66 \\
\hline 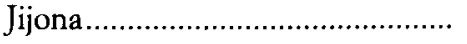 & 19,91 & 24,62 & 23,66 \\
\hline 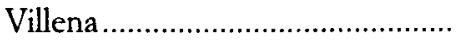 & 22,91 & 27,56 & 20,30 \\
\hline 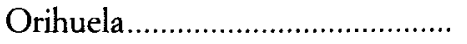 & 22,59 & 27,10 & 19,96 \\
\hline 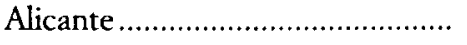 & 12,90 & 14,69 & 13,70 \\
\hline 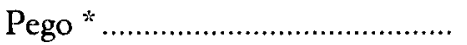 & 25,50 & 28,66 & 3,16 \\
\hline 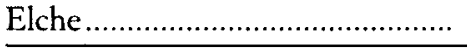 & 23,34 & 23,37 & 0,13 \\
\hline 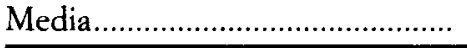 & 19,91 & 23,77 & 33,15 \\
\hline
\end{tabular}

FUENTES: BOPA de 14 de abril de 1844, 14 de diciembre de 1844 y 12 de noviembre de 1852. Para la población, $B O P A$ de 15 de marzo de 1850 y 3 de marzo de 1848 .

* He añadido a las cifras de población que ofrece el $B O P A$ en 1848 para el partido de Pego 9.878 habitantes que contaban los pueblos de Oliva, Pego, Fuente Encarroz, Potríes Rafelcofer y Vallonga que ya no pertenecían a la provincia de Alicante.

100, llegando a más del 60 por 100 si consideramos la cuota, es decir, el cupo con los recargos. De nuevo se aprecian unos grandes desequilibrios entre los diferentes municipios de la provincia. Elche experimenta una insignificante subida del 0,13 por 100 , Pego aumenta algo menos del 4 por 100, Alicante sufre una modesta subida cercana al 14 por 100 . Alcoy, Cocentaina, Jijona, Novelda y Villena suben entre un 20 y un 30 por 100 , mientras que Villajoyosa, Monóvar, Dolores y Callosa d'En Sarrià superan el 50 por 100 de incremento. Así, las protestas de Elda, Pinoso, Salinas y otros municipios estaban perfectamente justificadas, y denunciaban la forma interesada en que se repartían los cupos, sin sostenerse sobre una estadística de riqueza que justificara la contribución asignada. Esta situación fue denunciada en el Congreso en 1851 por el diputado Ignacio Argote, 
quien criticó «que se obligara a los pueblos a declarar como riqueza el 12 por 100 del cupo asignado» ${ }^{62}$. Los hacendados alicantinos, a través de la Junta de Agricultura, se limitaron a proponer reformas parciales, sin cuestionar el sistema fiscal ${ }^{63}$.

\section{CONCLUSIONES}

La reforma fiscal de Mon y Santillán fue parte esencial de un proyecto político conservador que decía representar los intereses de las clases medias. Sin embargo, la praxis política del moderantismo desmentía esta afirmación, y buena prueba de ello fue su política fiscal. El Estado cedió en parte la gestión de la contribución de inmuebles a las oligarquías locales, al permitir que la Diputación, los ayuntamientos y los mayores contribuyentes realizasen el reparto de los cupos y de las cuotas individuales. Ahora bien, éste se hizo sin que existiera una estadística previa de la riqueza que permitiera un reparto equitativo. Se partía de un defecto de base anterior a la reforma de 1845: la falta de datos; pero ni los delegados de Hacienda, ni mucho menos las oligarquías municipales hicieron un esfuerzo sincero para corregir ese defecto. Al no existir datos estadísticos, la asignación de los cupos a los pueblos era fruto de una negociación en el seno de la Diputación, mediatizada por el peso político de los municipios y la capacidad de influencia de los diputados. La misma situación se reproducía al repartir las cuotas individuales. No resulta extraño, pues, que muchos pueblos y contribuyentes protestaran unos repartos que consideraban arbitrarios e injustos. La gestión de la contribución de inmuebles evidencia el respeto que los sucesivos gobiernos moderados mostraron hacia unas oligarquías a las que necesitaban no solamente para poder desarrollar su acción ejecutiva, sino también para acceder al poder.

\section{BILIOGRAFIA}

Artola, M. (1986): La Hacienda del siglo xix. Progresistas y moderados, Madrid, Alicante.

${ }^{62}$ Pro (1992), p. 95

63 La Junta de Agricultura de Alicante, junto con la de Ciudad Real, propuso en 1853 que las tierras se clasificaran en cinco clases en lugar de tres, ya que su valor podía variar en función de su ubicación, especies de un mismo cultivo, antigüedad de los plantíos, etc. El Ministerio de Fomento aceptó la sugerencia y pidió opinión a otras Juntas, que se inclinaron por ampliar los tipos. Pro (1992), p. 95. 
AZAGRA, J. (1981): «Fiscalidad directa sobre el mundo rural valenciano en la segunda mitad del siglo XIX», Estudis d'Història Contemporània del País Valencià, núm. 2.

BaHAmonde, A., y ToRo, J. (1978): Burguesía, especulación y cuestión social en el Madrid del siglo XIX, Madrid, Siglo XXI.

Colomé, J. (1997): «Los amillaramientos como fuente documental histórica. Algunas reflexiones a partir del grado de ocultación detectado en las comarcas vitícolas catalanas», VI Congreso de la Asociación de Historia Económica, Girona.

Comin, F. (1988): Hacienda y economía en la España Contemporánea (1808-1936), Madrid, Instituto de Estudios Fiscales.

- (1994): «El fraude fiscal en la Historia: un planteamiento de sus fases», Hacienda Pública Española, núm. 1, pp. 31-46.

- (1996): Historia de la Hacienda Pública, II, España (1808-1995), Barcelona, Crítica.

- (1998): «Hacienda pública y crecimiento económico entre la reforma de Mon y la actualidad», en DE LA TORRE, J., y García-ZúNigA, M. (eds.): Hacienda y crecimiento económico. La reforma de Mon, 150 años después, Madrid, Marcial Pons.

Diaz Marin, P. (1997): Las estructuras de poder durante la Década Moderada: Alicante, 1844-1854, tesis doctoral, Universidad de Alicante.

- (1998): Después de la revolución. Centralismo y burguesía en Alicante (1844-1854), Alicante, Instituto de Estudios Juan Gil-Albart.

- (1999): «L'adaptació de les élites d'una nova capital provincial: Alacant sota el moderantisme», L'Avenç, núm. 233, Plecs d'Història local núm. 79.

Estape, F. (1971): La reforma tributaria de 1845, Madrid, Instituto de Estudios Fiscales.

Fontana, J. (1977): La revolución liberal (Politica y Hacienda, 1833-1845), Madrid, Instituto de Estudios Fiscales.

Fradera, J. M.: «Entre progresistes i moderats: La Diputació de 1840 a 1868», en História de la Diputació de Barcelona.

Guerra, J. R. (1848): Memoria redactada por el señor don José Rafael Guerra, Gefe Superior Politico de la Provincia de Alicante, en cumplimiento de lo dispuesto por el señor don José Maria del Castillo, Inspector de la Administración civil del Distrito, en sus oficios de 28 de julio, 1 y 14 de septiembre últimos, Alicante, José Marcili.

Madoz, P. (1995): Diccionario Geográfico-Estadístico-Histórico, Valencia, Librería Porres, Valencia.

Millán, J. (1999): El poder de la tierra. La sociedad agraria del Bajo Segura en la época del liberalismo, 1830-1890, Alicante, Institito de Estudios Juan Gil-Albert.

Pérez Picazo, M. ${ }^{\text {a }}$ T. (1998): «La Contribución Territorial. Propiedad y fraude fiscal», en De la Torre, J., y García-Zúñiga, M. (eds.): Hacienda y crecimiento económico. La reforma de Mon, 150 años después, Madrid, Marcial Pons.

PRo, J. (1992): Estado, geometría y propiedad. Los origenes del catastro en España (1715-1941), Madrid, Ministerio de Economía y Hacienda. 
- (1994): «El poder de la tierra: una lectura social del fraude en la contribución de inmuebles, cultivo y ganadería (1845-1936)», Hacienda Pública Española, núm. 1, pp. 189-201.

- (1995): «Ocultación de la riqueza rústica en España (1870-1936): acerca de la fiabilidad de las estadísticas sobre la propiedad y uso de la tierra», Revista de Historia Económica, núm. 1, pp. 89-112.

ROCA DE TOGORES, J. (1849): «Memoria sobre el estado de la agricultura en la provincia de Alicante, 1849», en Vidal OlIVARES, J. (1986): Materiales para la bistoria económica de Alicante, Alicante, Instituto de Cultura Juan Gil-Albert.

SALORT, S. (1998): La Hacienda local en la España contemporánea. La Hacienda municipal de Alacant (1800-1923), Alicante, Instituto de Estudios Juan Gil-Albert.

SEGURA, A. (1988): «La reforma de Mon (1845) y los amillaramientos de la segunda mitad del siglo XIX», en VARIOS AUTORES: El catastro en España 1714-1906 (vol. I), Ministerio de Economía y Hacienda.

VAlLEjO, R. (1997): «Los amillaramientos como fuente estadística: Una visión crítica desde la contribución territorial, 1845-1867», VI Congreso de la Asociación de Historia Económica, Girona.

VIDAL, J. (1994): «Fraude fiscal, Hacienda local y sistema tributario liberal: algunas repercusiones en el País Valenciano, 1845-1907», Hacienda Pública Española, núm. 1, pp. 281-287. 